Religare, ISSN: 19826605, v.16, n.2, dezembro de 2019, p.636-658

\title{
Um catolicismo em mutação: práticas sacramentais e desafeição religiosa observadas a partir da Paróquia São Sebastião, Diocese de Teófilo Otoni - MG
}

\author{
A changing catholicism: sacramental practices and religious \\ disenchantment observed from the Paróquia São Sebastião, \\ Diocese Teófilo Otoni - MG
}

Claudete Beise Ulrich ${ }^{1}$ Edison Lucas Fabricio ${ }^{2}$ Wagner Ferreira Vaz ${ }^{3}$

\section{Resumo}

Este artigo objetiva refletir sobre as mudanças pelas quais passa a Igreja Católica Romana, especificamente na Paróquia São Sebastião - Diocese de Teófilo Otoni/MG. Busca-se refletir a partir da seguinte problemática: quais fatores podem explicar a desafeição pelo catolicismo romano? Os conceitos de conversão, desafeição religiosa, trânsito e campo religioso, apoiados em Bourdieu, Hervieu-Léger, Berger, Domezi, Oliveira, bem como os dados do Censo IBGE de 2010 fundamentam teoricamente este estudo. A metodologia adotada é o estudo de caso, a partir de uma pesquisa realizada por ocasião das Santas Missões Populares, entre os dias 08 a 15 de outubro de 2017, com famílias residentes na área urbana e rural da Paróquia São Sebastião, na cidade de Carlos Chagas/MG. Assim, percebe-se uma tensão entre a declaração da catolicidade e a participação nos sacramentos, indicando para um Catolicismo em transformação.

Palavras-chave: Catolicismo; Desafeição religiosa; Transformação.

\section{Abstract}

This paper aims to reflect on the changes in the Roman-Catholic Church, specifically at the Parish São Sebastião - Diocese of Teófilo Otoni/MG. It starts from following issue: which factors can explain the emotional distance to the Roman Catholicism? The concepts of conversion, religious withdrawal, religious transit and environment,

\footnotetext{
${ }_{1}^{1}$ Doutora em Teologia (Faculdades EST). Pós-doutorado em História (UFSC). Pós-doutoranda em Educação (UFES). Professora na Graduação e no Programa de Pós-Graduação da Faculdade Unida em Vitória, ES. Coordenadora do Grupo de Pesquisa Religião, Gênero, Violências: Direitos Humanos (REGEVI) e Cátedra de Teologia Pública e Estudos da Religião, Faculdade Unida. E-mail: claudete@fuv.edu.br; Orcid: http://orcid.org/0000-0002-9830-3768

${ }^{2}$ Doutor em História - Universidade Federal de Santa Catarina. Professor de História na Universidade Regional de Blumenau. E-mail: edisonlucasf@hotmail.com; Orcid: http ://orcid.org/0000-0003-4337-4654 ${ }^{3}$ Mestre em Ciências da Educação - Unisal - Paraguai, Mestre em Ciências das Religiões Faculdade Unida de Vitória. E-mail: wagnerfilos15vaz@gmail.com; Orcid: http://orcid.org/0000-0001-9421-7312
} 
backed by Teixeira, Bourdieu, Hervieu-Léger, Berger, Domezi, Oliveira, and the data of the National Population Census from 2010 underpin theoretically this research. The applied methodology is a study of case from a research leaded, by the Santas Missões Populares (Holy Popular Missions), between October 8 and 15, 2017, with families of the urban and rural milieu of the Parish São Sebastião, at the town Carlos Chagas/MG. We perceive a tension between the declaration of catholicity and the participation in the sacraments, pointing to a Catholicism in transformation.

Keywords: Catholicism; Religious withdrawal; Transformation.

\section{Introdução}

A Igreja Católica Apostólica Romana vem perdendo fieis desde meados do século $X X$, em proporção bem acima da média de décadas anteriores. A última estatística do IBGE, 2010, mostrou um aumento significativo na migração de pessoas de tradição católica para outras denominações religiosas. Faustino Teixeira (2005, p. 16) aponta que “o catolicismo no Brasil revela uma grande complexidade. Trata-se de um campo religioso caracterizado por grande diversidade. A pluralidade é um traço constitutivo de sua configuração no Brasil." Necessita-se, portanto, falar em catolicismos no Brasil.

Pierre Bourdieu assinala que “[...] todo campo religioso é o lugar de uma luta [...]" (BOURDIEU, 1990, p. 120). O campo religioso brasileiro, portanto, é um espaço onde se disputa o poder e o capital religioso. Esta perspectiva ajuda-nos a compreender as intensas disputas existentes entre as várias instituições e agentes religiosos, as tentativas de legitimar-se em posições dominantes no campo religioso e em desqualificar a concorrência que busca angariar fieis.

Neste sentido, este artigo busca responder a seguinte pergunta problema: Quais fatores podem explicar a desafeição em relação ao catolicismo romano, evidenciado a partir da pesquisa das Santas Missões Populares na Paróquia São Sebastião, na cidade de Carlos Chagas - Diocese de Teófilo Otoni/MG? É sabido que não é possível responder a esta pergunta em sua totalidade, abrangendo toda a Diocese, mas sim, a partir de uma paróquia. Assim, os dados foram recolhidos da pesquisa realizada na Paróquia São Sebastião, em Carlos Chagas, por ocasião das Santas Missões Populares. 
Religare, ISSN: 19826605, v.16, n.2, dezembro de 2019, p.636-658

Antes de demonstrar os dados da pesquisa se faz necessário revisitar os principais teóricos que darão embasamento para analisar os resultados pesquisados.

No Brasil, a partir do processo de industrialização e urbanização, inicia uma mudança no campo religioso. A migração de muitas pessoas para as cidades, com o processo de industrialização e urbanização, coincidiu com o crescimento do Pentecostalismo, especialmente a partir da década de 1950. Conforme Paul Freston, a denominação Congregação Cristã do Brasil se instalou no país em 1910 e as Assembleias de Deus em 1911 (FRESTON, 1994, p. 70). A Igreja Católica viveu seu apogeu como religião oficial do país desde a chegada dos portugueses em 1500 até metade do século XX. Falava-se, até então, do Brasil como uma "Nação Católica" ou a "maior nação católica do mundo" (AZEVEDO, 2002, p. 31).

A chegada dos primeiros protestantes de imigração e de missão, no século XIX até a metade do século XX, não significou uma perda significativa de fiéis para a Igreja Católica. Os diferentes movimentos pentecostais e neopentecostais vêm ocupando os seus lugares no campo religioso e questionando a hegemonia católica no país. No entanto, é importante também apontar que a Igreja Católica procurou se renovar, especialmente a partir do Vaticano II. Segundo Guilherme Leonel, "pode-se definir esse percurso histórico como um esforço renovador da Igreja Católica; inicia-se durante o fim da primeira metade do século $X X$, ganhando maior intensidade e densidade ao longo da década de 1950, até culminar na ocorrência do Concílio Vaticano II" (LEONEL, 2010, p. 386).

Contudo, paralelamente a esse processo de diversificação do campo religioso ocorre também uma intensificação da secularização da sociedade. José de Jesús Legorreta Zepeda diz que “[...] este conjunto de mudanças pelo qual a religião perde sua relevância social, ideológica e institucional é o que genericamente chamamos secularização" (ZEPEDA, 2010, p. 129). No entanto, a religião está em constantes mudanças. O autor coloca que a religião:

Em vez de desaparecer, como haviam sugerido diversas vozes desde o século XIX, não somente resistia nas suas diversas formas, como 
também começava a se assistir com assombro um intenso e extenso surgimento de novos movimentos religiosos. O problema então já não seria como explicar o declínio da religião (questão para a qual tentava dar respostas a teoria da secularização), mas explicar sua grande exuberância na crise da modernidade globalizada. (ZEPEDA, 2010, p. 129-130).

A religião não está presente somente na esfera privada, mas circula com liberdade na esfera pública (BENCKE, 2015, p. 251). Desta forma, também as pessoas circulam de uma denominação a outra. Portanto, de acordo com Ronaldo de Almeida e Paula Montero:

O conceito weberiano de "conversão", que até muito recentemente explicava o complexo processo subjetivo de adesão a um novo credo, não parece mais capaz de elucidar essas rápidas idas e vindas entre religiões aparentemente tão díspares entre si: um processo interior em que a consciência religiosa não acusa, pelo menos à primeira vista, incongruências cognitivas (ALMEIDA; MONTERO, 2001, p. 92-101).

A conversão atualmente acontece dentro da própria instituição que se modifica como uma re-adesão à instituição religiosa. ${ }^{4} \mathrm{~A}$ conversão também é móvel, ela não garante a permanência numa instituição. Há também renovadas conversões, onde há a circulação dos sujeitos em diferentes instituições religiosas. Há uma dinâmica da recomposição do campo religioso brasileiro com a presença de um deslocamento de pessoas pelos diversos grupos religiosos (BARTZ, 2012, p.15). Para Emerson Roberto da Costa a análise do trânsito religioso apresenta-se como:

Uma chave interpretativa fundamental, visando reconhecer o componente principal na recomposição das formas religiosas. $\mathrm{Na}$ movimentação dos sujeitos é possível identificar uma dinâmica que permite hibridizações, motivada pelas múltiplas e temporárias demandas dos indivíduos religiosos, as quais relativizam o lugar da instituição, desenvolvendo novas identidades religiosas e sistemas simbólicos alternativos e provisórios. (COSTA, 2011, p. 33)

\footnotetext{
${ }^{4}$ Há novas imbricações e metamorfoses no ser religioso católico, por exemplo, a Renovação Carismática Católica. Consulte o livro de CARRANZA, Brenda. Renovação carismática católica: origens, mudanças e tendências. Aparecida: Santuário, 2000.
} 
Religare, ISSN: 19826605, v.16, n.2, dezembro de 2019, p.636-658

O termo trânsito religioso remete à ação de movimento e de fluxo. Pode-se inclusive falar no plural: trânsitos religiosos. Um sujeito pode estar visitando mais de uma instituição religiosa, construindo desta forma uma nova identidade religiosa, de dupla pertença. No movimento, no trânsito, realizam-se as hibridizações, e diferentes sistemas simbólicos alternativos e provisórios são construídos. Maria Cecilia Domezi aponta que "no Brasil de catolicismo obrigatório, historicamente o povo aprendeu a declinar-se no plural, adotando o sincretismo como moldura para continuamente definir e redefinir suas identidades" (DOMEZI, 2015, p. 241). O catolicismo também está passando por transformações no Brasil. Os censos do IBGE de 2000 e 2010 apontam para estas mudanças e para um intenso trânsito religioso. Para a pesquisadora Lázara Divina Coelho, é perceptível uma grande alternância de fiéis nas instituições religiosas:

Aguda circulação de pessoas pelas diversas instituições religiosas, descrita pelas pesquisas demográficas e sociológicas e a correspondente intensa circulação de ideias, crenças, etc., entre as religiões, gerando transformações no tempo e no espaço, das crenças e práticas reelaboradas nesse processo de justaposições, de diversas pertenças religiosas (COELHO, 2009, p. 9).

Percebe-se, portanto, que muitas pessoas estão circulando constantemente por diferentes instituições religiosas. Neste sentido, Ronaldo de Almeida e Paulo Montero apontam que estes movimentos são chamados pela literatura especializada de trânsito religioso. Segundo os autores:

Esta noção aponta, pelo menos, para um duplo movimento: em primeiro lugar, para a circulação de pessoas pelas diversas instituições religiosas, descrita pelas análises sociológicas e demográficas; e, em segundo, para a metamorfose das práticas e crenças reelaboradas nesse processo de justaposições, no tempo e no espaço, de diversas pertenças religiosas, objeto preferencial dos estudos antropológicos (ALMEIDA; MONTERO, 2001, p. 93).

O trânsito religioso, além da circulação das pessoas por diferentes instituições, também aponta para as reelaborações no tempo e no espaço nas diferentes pertenças religiosas. Segundo Domezi: 
[...] a religiosidade matricial brasileira tem força agregadora, está sempre em mutação e é pouca afeita à delimitação de fronteiras entre os diferentes sistemas simbólicos e religiosos. Atualmente vem sendo retomada e revitalizada de novas maneiras, especialmente pelas novas formas de pentecostalismo, que em resposta às demandas mágicas da sociedade de consumo, provocam a reformulação de antigas crenças e práticas cristãs (DOMEZI, 2015, p. 234).

Ainda nessa linha de raciocínio, Peter Berger ajuda a compreender como se dá essa disputa em campos cada vez mais diversificados. Na visão desse autor, o pluralismo que a modernidade construiu coloca as instituições religiosas diante de uma típica situação de mercado, elas podem "fazer o jogo pluralista da livre empresa religiosa, [...] modificando o seu produto de acordo com a demanda do consumidor" (2004, p. 163). Berger vai mais fundo ainda nessa reflexão. Para ele,

a tradição religiosa, que antigamente podia se impor pela autoridade, agora tem que ser colocada no mercado. Ela tem que ser "vendida" para uma clientela que não está mais obrigada a "comprar". A situação pluralista é, acima de tudo, uma situação de mercado. Nela, as instituições religiosas tornam-se exigências de mercado e as tradições religiosas tornam-se comodidades de consumo. E, de qualquer forma, grande parte da atividade religiosa nessa situação vem a ser dominada pela lógica da economia de mercado (2004, p. 149).

Ainda sobre as mudanças do campo religioso contemporâneo, Danièle HervieuLéger, fazendo refletindo sobre a religião a partir da França, ajuda a entender, em parte, o que está acontecendo com o catolicismo no Brasil. Está se caminhando velozmente de um país rural para um país urbano. De acordo com a autora, “a igreja era o ponto de referência, o lugar em que se concentrava toda a vida da comunidade. As festas religiosas regulavam os ciclos da vida dos indivíduos e da coletividade. $\mathrm{Na}$ vida rural ou na cidade pequena o sino da matriz definia a vida" (HERVIEU-LÉGER, 2008, p. 15-16).

Neste sentido, Pedro Assis Ribeiro de Oliveira afirma que há necessidade de se criar relações de afeto e de pertença, a partir das mediações que se estabelece na comunidade religiosa. Segundo Oliveira a desafeição religiosa apresenta: 
Religare, ISSN: 19826605, v.16, n.2, dezembro de 2019, p.636-658

i) $\mathrm{O}$ enfraquecimento ou ruptura do laço afetivo que une o fiel à instituição religiosa, o que indica a afeição como sentimento, ii) a descrença do fiel em um ou mais artigos da fé professada pela Igreja; e iii) o afastamento pessoal das práticas rituais que ligam fiel à Igreja (OLIVEIRA, 2012, p. 1250).

A seguir, apresentamos alguns aspectos do contexto onde se realizou a pesquisa, sendo que a mesma se realizou na Paróquia São Sebastião, na cidade Carlos Chagas, Diocese de Teófilo Otoni.

\section{Localizando o contexto da pesquisa: Diocese de Teófilo Otoni e Paróquia São Sebastião na Cidade de Carlos Chagas - MG}

Teófilo Otoni é um município brasileiro no interior do estado de Minas Gerais, criado em 7 de setembro de 1853. A cidade localiza-se no vale do Rio Mucuri, a nordeste de Belo Horizonte, capital do Estado. Ela ocupa uma área de 3.242 km², sendo que $19,62 \mathrm{~km}^{2}$ estão em perímetro urbano. Sua população foi estimada no último Censo, de 2010 em 134.745 pessoas. A maioria da população participa da Igreja Católica.

Os primeiros imigrantes a chegar à região de Teófilo Otoni eram de tradição luterana. O primeiro culto foi celebrado no dia 29 de maio de 1862, com a chegada do Pastor Johann Leonhardt Hollerbach. O culto se realizou na residência do Diretor da Companhia de Colonização. No dia 9 de junho do mesmo ano foi inaugurado o primeiro templo da comunidade ${ }^{5}$. Os luteranos estão em Teófilo Otoni desde a colonização. Todavia, como igreja de imigração, não fazia parte de sua atuação o proselitismo. Assim, durante muitos anos, ela permaneceu uma igreja étnica e foi somente nas últimas décadas que ela se inseriu e se assumiu como Igreja Evangélica de Confissão Luterana no Brasil, desde $1962^{6}$. Portanto, aqui tem um dado interessante,

\footnotetext{
${ }^{5}$ COMUNIDADE EVANGÉLICA DE CONFISSÃO LUTERANA EM TEÓFILO OTONI - CETO. Disponível em: <http://www.luteranos.com.br/conteudo_organizacao/teofilo-otoni/historico-dacomunidade-evangelica-de-teofilo-otoni>. Acesso em: 20 fev. 2019.

${ }^{6}$ O nome Igreja Evangélica de Confissão Luterana no Brasil (IECLB) surge em 1962 com a união dos quatro Śnodos presentes nas diversas regiões do Brasil. Em termos eclesiásticos, os evangélicos luteranos não constituíam uma Igreja estruturada juridicamente em nível nacional. Havia quatro
} 
Religare, ISSN: 19826605, v.16, n.2, dezembro de 2019, p.636-658

a primeira igreja de Teófilo Otoni não foi a Católica e sim a dos colonos imigrantes luteranos.

A Diocese de Teófilo Otoni foi criada no dia 27 de novembro de 1960, pela Bula "Sicut Virentes", do Papa João XXIII. Ela ocupa uma área de 24.600 km², desmembrada da Diocese de Araçuaí/MG. Ela abarca geograficamente parte do Vale do Rio Doce Cidades como Franciscóplis, Itambacuri, Frei Inocêncio; Vale do Rio São Mateus Sul toda a região de Mantena; Vale do São Mateus Norte - as cidades de Frei Gaspar, Ouro Verde e Ataléia; Vale do Mucuri tem sua extensão maior, as cidades como Ladainha, Poté, Novo Oriente, Pavão, Águas Formosas, Teófilo Otoni, Carlos Chagas e Nanuque, sendo essas as principais cidades desse vale. Um fato chama atenção dentre as cidades da Diocese, a cidade de Mantena, de acordo com o Censo IBGE 2010, é de maioria protestante.

A população da área que abarca a Diocese de Teófilo Otoni, que vai além da cidade de Teófilo Otoni, conta com 478.448 pessoas, destas 323.850 declararam-se católicas, 113.451 são protestantes, 2.456 Espíritas, 25.581 sem religião. A Diocese de Teófilo Otoni conta hoje com 35 cidades; 42 Paróquias; 161 Comunidades urbanas; 534 Comunidades rurais e 46 padres para o serviço religioso às comunidades. O gráfico abaixo apresenta os dados da população das cidades, o número de católicos, de protestantes, de espíritas e sem religião da Diocese de Teófilo Otoni/MG (Dados IBGE 2010).

Sínodos independentes: Sínodo Rio-grandense, Sínodo Evangélico-Luterano de Santa Catarina, Paraná e outros Estados, Sínodo Evangélico e Sínodo Evangélico do Brasil-Central. SCHÜNEMANN, Rolf. Do gueto à participação: o surgimento da consciência sociopolítica na IECLB entre 1960 e 1975. São Leopoldo: Sinodal, 1992. p. 43. 
Religare, ISSN: 19826605, v.16, n.2, dezembro de 2019, p.636-658

Gráfico 1 - Demonstração da população religiosa e não religiosa na Diocese de Teófilo Otoni - Dados do Censo IBGE 2010.

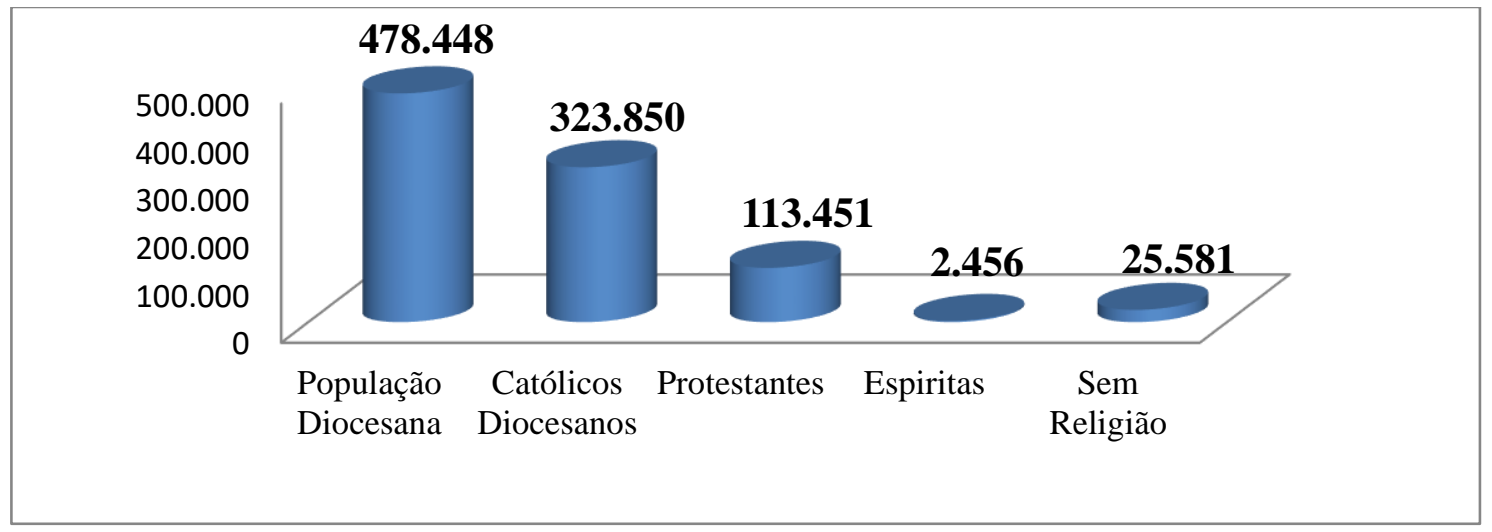

Fonte: Dados IBGE 2010

Ao analisar o gráfico em dados de percentagem, percebe-se: $70 \%$ da população da Diocese de Teófilo Otoni professam o catolicismo; $24 \%$ se apresentam como protestantes; $5 \%$ sem religião e 1\% são espíritas. Para analisar com mais profundidade as mudanças operadas qualitativamente no interior do catolicismo, foi escolhida a Paróquia São Sebastião de Carlos Chagas/MG, onde a pesquisa foi realizada entre os dias 08 a 15 de outubro de 2017, por ocasião das Santas Missões Populares.

\section{Apresentação dos dados e resultados da pesquisa: Santas Missões Populares (SMP) - Paróquia São Sebastião - Carlos Chagas/MG}

A pesquisa foi realizada somente na extensão da Paróquia São Sebastião de Carlos Chagas/MG, pertencente à microrregião de Nanuque e à mesorregião do vale do Rio Mucuri. Ela tem uma área de $3.202 \mathrm{~km}^{2}$, uma população estimada em 20.087 habitantes e uma densidade de 6,28 habitantes por $\mathrm{km}^{2}$. A paróquia soma 32 comunidades.

O estudo de caso analisado utilizou-se da estrutura das Santas Missões Populares e do trabalho de 750 pessoas (denominadas missionários/as pesquisadores/as) nelas envolvidas. Desta forma, os/as missionários/as pesquisadores/as tiveram três treinamentos subsequentes, onde os/as mesmos/as puderam estudar a metodologia da pesquisa; fizeram os treinamentos e, de posse do 
Religare, ISSN: 19826605, v.16, n.2, dezembro de 2019, p.636-658

questionário da pesquisa, foram a campo colher as informações que em momento posterior foram tabuladas e estão disponíveis em forma de tabela neste artigo.

Como as Santas Missões Populares têm como objetivo principal a evangelização, serviu de referência documental os textos bíblicos e o manual redigido para as Santas Missões Populares do Pe. Luís Mosconi - "Uma Experiência de Evangelização voltada para o Povo". Este material foi à base dos dois primeiros encontros. O terceiro encontro de formação contou com o treinamento dos missionários/as pesquisadores/aspara a realização da pesquisa. A metodologia utilizada para a investigação foi mista, usando os recursos da pesquisa quantitativa e qualitativa (entrevistas - questionários). Neste artigo, vamos apresentar apenas os dados quantitativos da pesquisa.

No último encontro formativo foi feito a prova piloto do questionário para testar sua eficácia. Os resultados alcançados pelos/as pesquisadores/as foram satisfatórios. A prova piloto indica que foi aplicado o teste para averiguar se o questionário não oferecia dificuldades de compreensão para aqueles/as que estavam participando como entrevistadores/as. Em seguida, utilizou-se, então, o recurso do aparelho data show, onde já foram sendo lançados os resultados preliminares e organizadas as tabelas. Desta forma, todos puderam participar e verificar a simulação do resultado. O sucesso da prova piloto indicou que os/as pesquisadores/as estavam preparados/as para ir a campo e realizar a pesquisa. Cumpre destacar que os investimentos financeiros para o levantamento dos dados foram aprovados pela Assembleia Paroquial, estando previstos no orçamento da Paróquia São Sebastião de Carlos Chagas/MG de 2017 e aprovado pelo CEAP (Conselho Econômico e Administrativo Paroquial) e CPP (Conselho de Pastoral Paroquial).

Contudo, todos foram treinados com a mesma metodologia para executar as ações das Santas Missões Populares, através de entrevista e respostas ao questionário. Assim, foram visitadas 3.675 famílias católicas e 817 evangélicas/protestantes, totalizando 4.492 domicílios. Foram visitadas, ao todo, 10.787 pessoas. Destas, 5.124 
pessoas residem no meio urbano e 5.663 em áreas rurais. O resultado encontra-se na tabela abaixo e nos gráficos interpretativos subsequentes a ela.

Tabela 1 - Resultado da pesquisa - Paróquia São Sebastião - Carlos Chagas - 08 a 15 de outubro de 2017.

\begin{tabular}{|c|c|c|c|c|c|c|c|c|c|c|c|c|c|c|c|c|c|c|c|c|c|c|c|c|c|}
\hline \multirow{3}{*}{ Comunidades } & \multirow{2}{*}{\multicolumn{2}{|c|}{ 1- Ses Fasília é: }} & \multirow{2}{*}{\multicolumn{2}{|c|}{\begin{tabular}{|l|} 
2- Foras \\
Católicos? \\
\end{tabular}}} & \multirow{2}{*}{\multicolumn{2}{|c|}{ 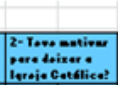 }} & \multirow{2}{*}{\multicolumn{2}{|c|}{ 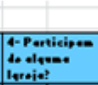 }} & \multirow{2}{*}{\multicolumn{4}{|c|}{\begin{tabular}{|l|} 
S- Sea tamélia participa das \\
celebraşos - Católicas
\end{tabular}}} & \multirow{2}{*}{\multicolumn{3}{|c|}{$\begin{array}{l}\text { 6. Quastas pessoss } \\
\text {-oras resta casa? }\end{array}$}} & \multicolumn{10}{|c|}{ 7- Todos Sáo Sacramentados? } \\
\hline & & & & & & & & & & & & & & & & \multicolumn{2}{|c|}{ Betixctes } & \multicolumn{2}{|c|}{ renenti- } & \multicolumn{2}{|c|}{ crirs.etes } & \multicolumn{4}{|c|}{ 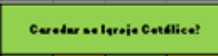 } \\
\hline & Católic & Evan & Sim & Nä๋ & Sim & Näo & Sim & Näo & Sim & $\begin{array}{l}\text { Poucas } \\
\text { rezes }\end{array}$ & Nä่ & CatlE & Catól. & Evang & Evicat & Sim & falta & Sim & Falta & $\operatorname{sim}$ & Falta & Sim & \begin{tabular}{|l|l|} 
Năo \\
\end{tabular} & Deseja & Nảo \\
\hline Amigos Jesus & 161 & 60 & 49 & 11 & 26 & 34 & 56 & 4 & 58 & 87 & 13 & 3 & 312 & 180 & 0 & 281 & 31 & 181 & 131 & 148 & 164 & 62 & 99 & 25 & 74 \\
\hline Assentamento & 69 & 31 & 25 & 6 & 20 & 11 & 27 & 4 & 25 & 27 & 17 & 8 & 135 & 0 & 6 & 95 & 40 & 72 & 63 & 59 & 76 & 28 & 41 & 17 & 24 \\
\hline Bela Vista & 63 & 6 & 3 & 3 & 4 & 2 & 6 & 0 & 16 & 41 & 6 & 0 & 177 & 14 & 0 & 170 & 7 & 130 & 47 & 112 & 65 & 46 & 17 & 14 & 3 \\
\hline Bom Jesus & 147 & 40 & 30 & 10 & 24 & 16 & 33 & 7 & 62 & 68 & 17 & 0 & 348 & 100 & 0 & 326 & 22 & 263 & 85 & 233 & 115 & 60 & 87 & 41 & 46 \\
\hline Brejaúba & 63 & 9 & 9 & 0 & 5 & 4 & 9 & 0 & 25 & 15 & 23 & 0 & 198 & 18 & 0 & 177 & 21 & 118 & 80 & 99 & 99 & 45 & 18 & 10 & 8 \\
\hline Capoeiras & 107 & 13 & 9 & 4 & 0 & 13 & 13 & 0 & 8 & 75 & 24 & 0 & 284 & 27 & 12 & 239 & 45 & 137 & 147 & 112 & 172 & 41 & 66 & 25 & 41 \\
\hline Colônia & 254 & 66 & 49 & 17 & 49 & 17 & 62 & 4 & 71 & 152 & 31 & 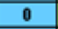 & 661 & 159 & 2 & 615 & 46 & 479 & 182 & 440 & 221 & 168 & 86 & 9 & 45 \\
\hline Córação d & 127 & 24 & 24 & 0 & 10 & 14 & 24 & 0 & 13 & 101 & 12 & 1 & 150 & 35 & 0 & 119 & 31 & 99 & 51 & 98 & 52 & 56 & 71 & 25 & 46 \\
\hline Cómrego de Areia & 35 & 2 & 5 & 1 & 1 & 1 & 0 & 2 & 12 & 10 & 13 & 0 & 91 & 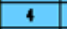 & 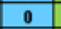 & 91 & 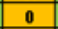 & 90 & 1 & 86 & 5 & 24 & 11 & 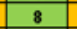 & 3 \\
\hline Córrego Seco & 32 & 3 & 2 & 1 & 1 & 2 & 2 & 1 & 18 & 12 & 2 & 0 & 83 & 8 & 0 & 81 & 2 & 57 & 26 & 50 & 3 & - & 24 & 0 & 14 \\
\hline Cristal & 16 & 1 & 1 & 0 & 1 & 0 & 1 & 0 & 8 & 5 & 2 & 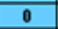 & 46 & 1 & 0 & 43 & 3 & 35 & 11 & 31 & 15 & 10 & 6 & 2 & 4 \\
\hline Francisc & 51 & 3 & 3 & 0 & 0 & 3 & 3 & 0 & 5 & 46 & 0 & 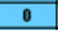 & 133 & 0 & 0 & 121 & 12 & 90 & 43 & 61 & 72 & 12 & 39 & 17 & 22 \\
\hline Matriz São Sebastiáo & 965 & 288 & 235 & 53 & 100 & 188 & 158 & 130 & 269 & 487 & 178 & 31 & 2781 & 357 & 16 & 2438 & 343 & 1784 & 997 & 1569 & 1212 & 535 & 430 & 161 & 269 \\
\hline Pam Pam & 4 & 3 & 3 & 0 & 2 & 1 & 3 & 0 & 13 & 22 & 10 & 0 & 110 & 13 & 0 & \begin{tabular}{|l|}
100 \\
\end{tabular} & 10 & 64 & 46 & 52 & 58 & 20 & 25 & 13 & 12 \\
\hline Prateados & 35 & 7 & 5 & 2 & 3 & 4 & 5 & 2 & 10 & 8 & 17 & 0 & 85 & 20 & 0 & 55 & 30 & 37 & 48 & 30 & 55 & 20 & 15 & 9 & 6 \\
\hline Presidente Pena & 226 & 23 & 21 & 2 & 10 & 13 & 22 & 1 & 58 & 64 & 85 & 19 & 619 & 70 & 4 & 559 & 60 & 338 & 281 & 281 & 338 & 140 & 86 & 28 & 58 \\
\hline Quilômbolas & 6 & 26 & 26 & 0 & 20 & 6 & 26 & 0 & 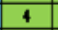 & 25 & 31 & 0 & 133 & 26 & 0 & 123 & 10 & 53 & 80 & 36 & 97 & 22 & 38 & 8 & 30 \\
\hline Quim Quim & 54 & 3 & 2 & 1 & 2 & 1 & 3 & 0 & 1 & 50 & 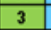 & 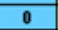 & 167 & 10 & 0 & 139 & 28 & 72 & 95 & 69 & 98 & 15 & 39 & 21 & 18 \\
\hline Santa Cruz & 44 & 0 & 0 & 0 & 0 & 0 & 0 & 0 & 19 & 25 & 0 & 0 & 44 & 0 & 0 & 44 & 0 & 40 & 4 & 38 & 6 & 30 & 14 & 2 & 12 \\
\hline Santa Rita & 97 & 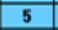 & 2 & 3 & $=$ & 8 & 2 & 3 & 27 & 62 & 8 & 0 & 135 & 10 & 0 & 95 & 40 & 105 & 30 & 105 & 30 & 40 & 57 & 15 & 42 \\
\hline Santa Terezinh & 23 & 2 & 2 & 0 & 1 & 1 & 2 & 0 & 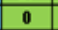 & 18 & 5 & 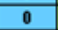 & 72 & 3 & 0 & 69 & 3 & 26 & 46 & 17 & 55 & 9 & 14 & 9 & 5 \\
\hline Santos Reis & 71 & 15 & 11 & 4 & 7 & 8 & 15 & 0 & 21 & 30 & 12 & 8 & 153 & 27 & 32 & 143 & 10 & 128 & 25 & 103 & 50 & 40 & 31 & 17 & 14 \\
\hline Săo Nicolau & 33 & 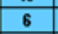 & 5 & 1 & 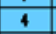 & 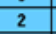 & 6 & o & $\cdots$ & 28 & 0 & 0 & 87 & $\cdots$ & 0 & 67 & 20 & 45 & 42 & 35 & 52 & 10 & 23 & 10 & 13 \\
\hline Sáo Bento & 23 & 0 & 0 & 0 & 0 & 0 & 0 & 0 & 4 & 16 & 3 & 0 & 67 & 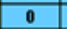 & 0 & 55 & 12 & 38 & 29 & 38 & 29 & 8 & 15 & 7 & 8 \\
\hline São Geraldo & 256 & 44 & 34 & 10 & 9 & 35 & 37 & 7 & 58 & 135 & \begin{tabular}{|l|l|}
63 \\
\end{tabular} & 0 & 573 & 129 & 0 & 509 & 64 & \begin{tabular}{|l|l}
307 \\
\end{tabular} & 266 & 250 & 323 & 92 & 164 & 65 & 99 \\
\hline Sáo d & 172 & 31 & 21 & 10 & 6 & 25 & 28 & 3 & 62 & 75 & 31 & 4 & 268 & 96 & 4 & 229 & 39 & 178 & 90 & 144 & 124 & 70 & 102 & 42 & 60 \\
\hline São Juliāo & 34 & 6 & 5 & 1 & 4 & 2 & 6 & 0 & 5 & 29 & 0 & 0 & 127 & 16 & 0 & 114 & 13 & 72 & 55 & 56 & 71 & 15 & 19 & 9 & 10 \\
\hline Tabocal de Cim & 64 & 4 & 4 & 0 & 2 & 2 & 4 & 0 & 17 & 10 & 37 & 0 & 190 & 6 & 0 & 177 & 13 & 125 & 65 & 115 & 75 & 37 & 27 & 8 & 19 \\
\hline Três Pedras & 25 & 13 & 13 & 0 & 10 & 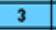 & 12 & 1 & 11 & 10 & 4 & 0 & 63 & 27 & 0 & 62 & 1 & 47 & 16 & 53 & 10 & 14 & 11 & 3 & 8 \\
\hline Vila Pereira & 323 & 83 & 69 & 14 & 19 & 64 & 25 & 58 & 108 & 51 & 138 & 26 & 837 & 201 & 21 & 488 & 349 & 374 & 463 & 359 & 478 & 168 & 155 & 80 & 75 \\
\hline Total & 3675 & 817 & \begin{tabular}{|l|l|}
663 \\
\end{tabular} & 154 & 345 & 472 & \begin{tabular}{|l|}
590 \\
\end{tabular} & 227 & \begin{tabular}{|l|}
1014 \\
\end{tabular} & 1784 & \begin{tabular}{|l|}
785 \\
\end{tabular} & 92 & 9129 & 1561 & 97 & 7824 & \begin{tabular}{|l|}
305 \\
\end{tabular} & 5584 & 3545 & \begin{tabular}{|c|c|}
4879 \\
\end{tabular} & 4250 & \begin{tabular}{|l|}
1845 \\
\end{tabular} & \begin{tabular}{|c|}
1830 \\
\end{tabular} & 742 & 1088 \\
\hline
\end{tabular}

Fonte. Elaborada pelos autores.

Este quadro aponta para as localidades da Paróquia São Sebastião, cidade de Carlos Chagas, Diocese Teófilo Otoni, que foram visitadas. Os/as missionários/as pesquisadores/as visitaram famílias católicas e protestantes, meio urbano e rural. O gráfico abaixo exemplifica os dados comparativos entre IBGE 2010 e os resultados da pesquisa das Santas Missões Populares de 2017 em relação aos domicílios da cidade de Carlos Chagas. 


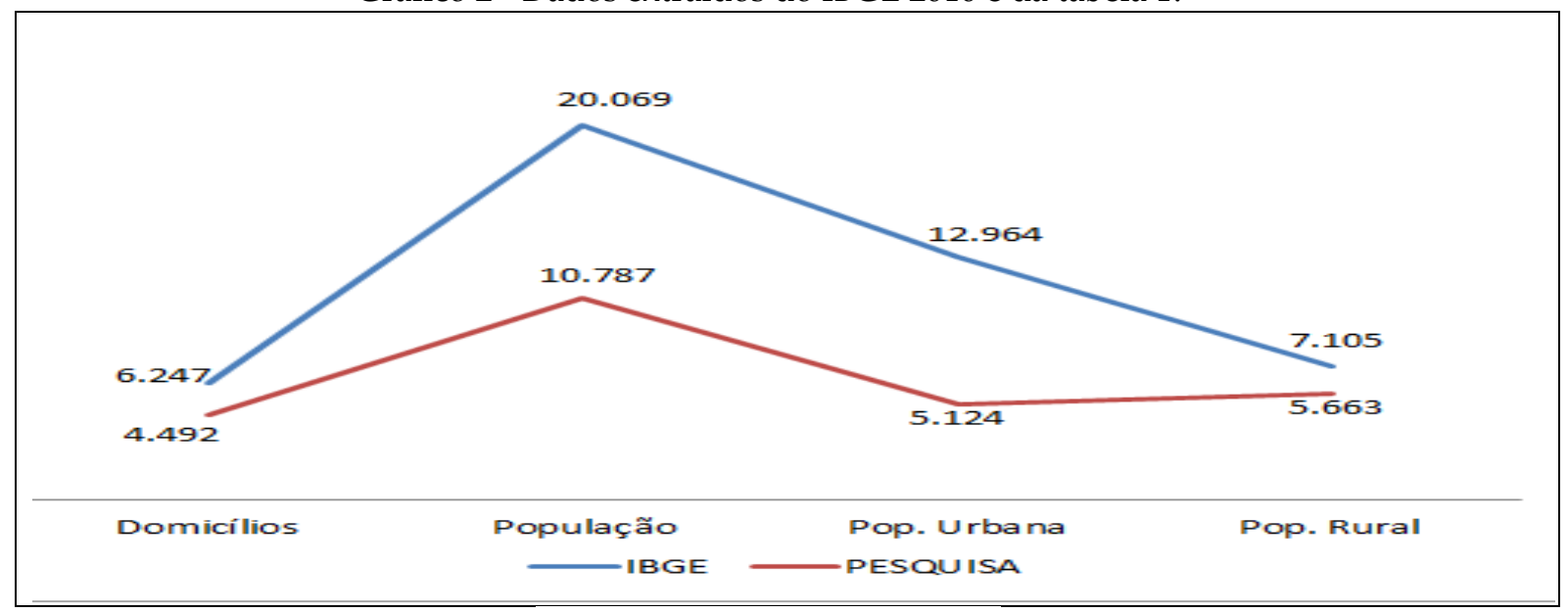

Fonte: Elaborado pelos autores

Os dados do IBGE afirmam que há no município de Carlos Chagas 6.247 domicílios. Destes, os/as pesquisadores/as populares visitaram 4.492. Assim, os/as pesquisadores/as conseguiram visitar $72 \%$ dos domicílios. Os dados do IBGE apontam que a população é de 20.069 e a pesquisa alcançou 10.787 pessoas. Os/as missionários/as pesquisadores/as, portanto, entrevistaram $54 \%$ da população deste município. Em relação à população urbana, o IBGE registra 12.964 pessoas e destas conseguiu-se entrevistar apenas 5.124, num total de 40\% dos moradores da cidade. Em relação à população rural, o IBGE registra 7.105 pessoas, dos quais os/as pesquisadores/as populares conseguiram entrevistar 5.663, alcançando $80 \%$ dos domicílios. Pode-se dizer que a recepção dos/as missionários/as pesquisadores/as no meio rural tiveram um êxito maior que na cidade. Outro dado importante é que a Igreja Católica Apostólica Romana, nesta região, tem mais comunidades na área rural. $\mathrm{O}$ gráfico abaixo apresenta questões específicas da situação religiosa da região abrangida pela Paróquia São Sebastião de Carlos Chagas. 
Religare, ISSN: 19826605, v.16, n.2, dezembro de 2019, p.636-658

Gráfico 3 - Dados extraído da tabela 1 - Perguntas: Sua família é católica? Foram católicos? Participa de outra igreja Protestante?

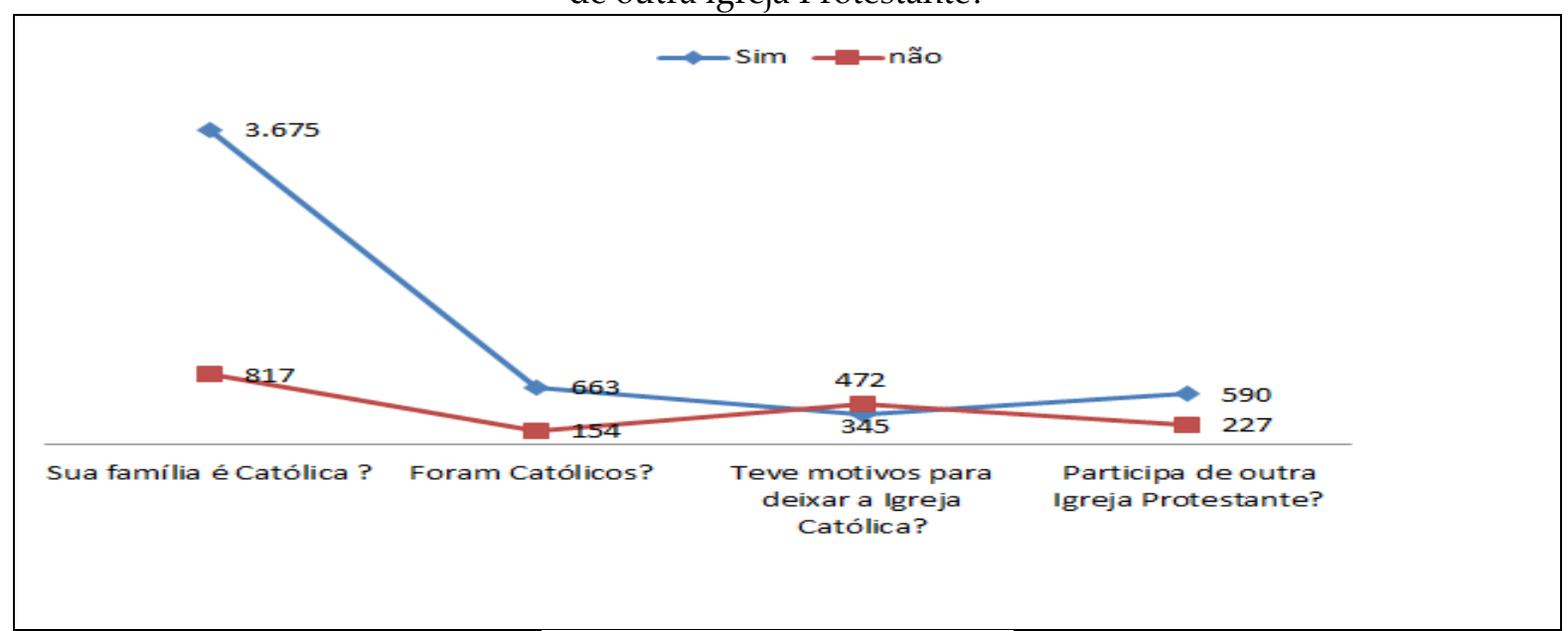

Fonte: Elaborado pelos autores

Do gráfico acima é possível colher informações importantes. Dos 4.492 questionários respondidos, 3.675 famílias afirmaram ser católicas e 817 responderam ser protestantes /evangélicas. Destas últimas, 663 famílias afirmaram que um dia já foram católicas e 154 vieram do protestantismo. Ao serem perguntadas se tiveram motivos para deixar a Igreja Católica, 345 famílias afirmaram que sim, 472 disseram que não. Dentre as 817 pessoas que se declararam não católicas, 590 afirmaram frequentar alguma igreja e 227 afirmam que não participam de reuniões religiosas.

A partir da pesquisa, constatou-se que $18 \%$ dos/as entrevistados/as afirmaram que são protestantes nas mais diversas igrejas dentro do município e 82\% são católicos. Contudo, seguindo os dados do censo do IBGE, de 2010, observa-se que $25 \%$ da população do município não são católicos e 75\% são católicos. Essa discrepância ocorreu, em grande medida, pelo fato de os/as pesquisadores/as não terem conseguido visitar todos os domicílios.

Os/as pesquisadores/as, ao fazer a pergunta para os entrevistados se já "foram católicos"? Eles/as receberam a resposta positiva de $81 \%$ e a negativa de $19 \%$, que afirmaram nunca ter estado na Igreja Católica. Assim, é possível perceber que é relativamente baixo o número de pessoas já nascidas em denominações protestantes. E ao serem indagadas se participavam de outra Igreja, 72\% afirmaram que estavam engajadas em outras Igrejas Protestantes, enquanto, $28 \%$ estão fora de qualquer 
Religare, ISSN: 19826605, v.16, n.2, dezembro de 2019, p.636-658

denominação religiosa. Um dado curioso que a pesquisa levantou é que muitas famílias não estão participando da religião para as quais um dia se converteram. Os dados apontaram que das 817 famílias cristãs protestantes no município pesquisado, 227 famílias responderam que estão afastadas das suas respectivas igrejas.

Essas pessoas que se denominaram sem religião já foram católicas, depois se tornaram protestantes e atualmente declaram-se sem religião. É um número que vem crescendo, primeiro devido às decepções que um dia tiveram na igreja católica, e depois devido a não resolução dos mesmos conflitos em outras denominações religiosas. Entre as justificativas apresentadas ao responder os questionários, destacase a resposta que se repetiu: "se acredita em Deus, mas não pertence a nenhuma instituição religiosa". Na conclusão do gráfico, pode-se dizer que do total de pessoas que deixaram a Igreja Católica, 42\% afirmam que tiveram motivos para tal, enquanto 58\% simplesmente saíram sem uma causa específica.

O próximo gráfico aponta uma questão que não é formulada pelo Censo do IBGE. As entrevistas realizadas pelos/as missionários/as populares buscaram saber quantos católicos são praticantes e quantos são apenas católicos por tradição, ou seja, apenas católicos nominais. Ao apurar os resultados da pesquisa, apareceu a primeira surpresa. Em algumas residências, ao perguntar se, "sendo sua família católica, ela participa das celebrações?" (pergunta 5 da tabela 1), descobriu-se que o número de famílias católicas assíduas nas celebrações/missas é razoavelmente baixo, somando pouco mais de 1.014 famílias participantes das celebrações/missas ao longo da semana. Ao contrário, 1.784 famílias responderam que vão poucas vezes às celebrações, principalmente em momentos importantes como: no dia em que os filhos recebem algum sacramento, ou em casamentos de amigos e às vezes nas missas de sétimo dia de parentes e amigos próximos. Surpreende o dado de que 785 famílias nunca vão à Igreja e 92 famílias participam de mais de uma religião.

Gráfico 4 - Sua família participa das celebrações católicas aos domingos? 
Religare, ISSN: 19826605, v.16, n.2, dezembro de 2019, p.636-658

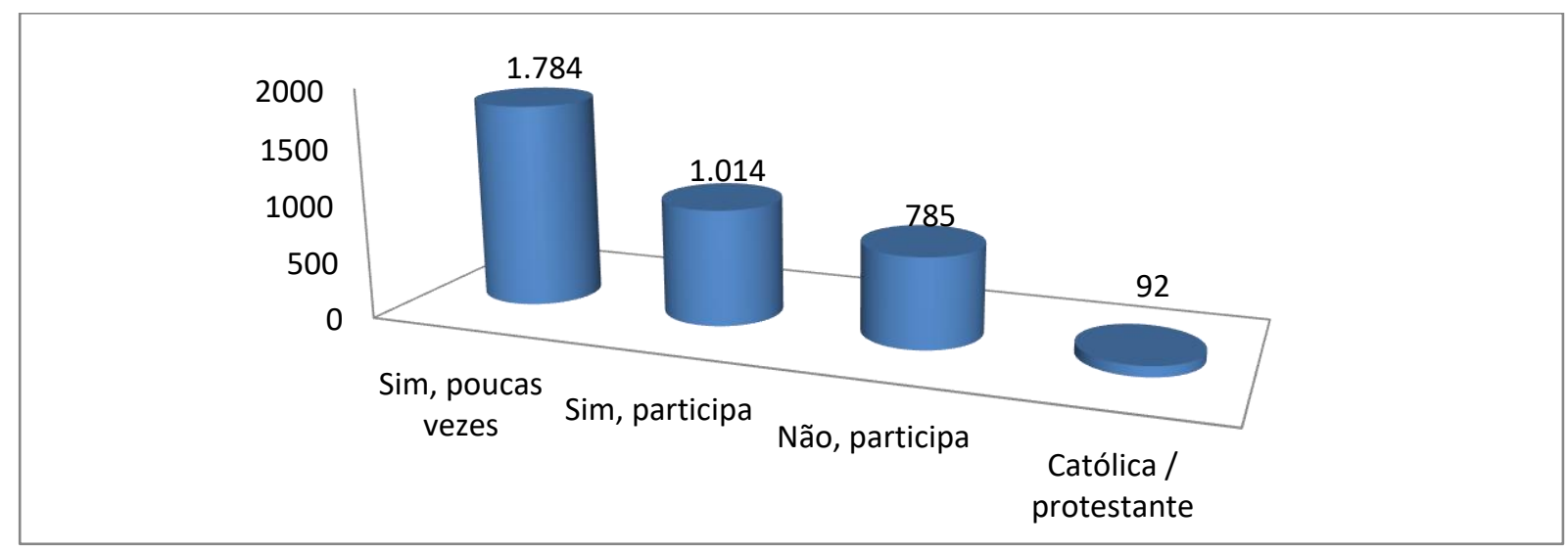

Fonte. Elaborada pelos autores

Quando o IBGE afirma que o número de fiéis católicos diminuiu de um censo para o outro, a realidade pode ser ainda mais complexa. Ao fazer a estimativa entre o número de entrevistados que afirmaram ser católicos e os que participam da vida da Igreja Católica nas celebrações, aproxima-se da cifra de $23 \%$ de um contingente de 9.129pessoas. Portanto, 77\% são apenas fiéis católicos nominais, pois nem mesmo receberam o sacramento de iniciação religiosa. (cf. tabela 1 - pergunta 6).

Analisando os resultados, chega-se à conclusão de que a Igreja Católica tem um contingente muito alto de católicos que não assumem a prática do catolicismo em sua dimensão sacramental. São fieis que não nutrem uma preocupação em participar dos aspectos mais ordenadores da vida eclesial. Ao auscultar os dados fica perceptível que as comunidades rurais estiveram mais abertas para responder o questionário que a população das áreas urbanas. Para efeitos práticos, talvez esteja aqui um dos elos perdidos da Igreja. A instituição ainda não conseguiu criar uma metodologia que atenda a população urbana, pois a pesquisa demonstrou que o modelo paroquial atual responde muito mais ao mundo rural do que às estruturas urbanas.

Ao chegar à última pergunta da tabela 1, na pergunta de número 7, entra-se na participação sacramental. Nesse bloco de respostas, pode-se afirmar que a pesquisa realizada através das Santas Missões Populares permite afirmar, a partir do universo particular da Paróquia de São Sebastião, que o mundo católico está passando por uma transformação. Pois, ao analisar o distanciamento que os católicos estão assumindo 
Religare, ISSN: 19826605, v.16, n.2, dezembro de 2019, p.636-658

mediante a participação nos sacramentos, percebe-se uma "desafeição religiosa" (OLIVEIRA, 2012, p. 12-33) para com um catolicismo sacramental.

Do total de 9.129 pessoas que na pesquisa afirmaram ser católicas, 7.824 são batizadas na e 1.305 pessoas ainda não foram batizadas. Pois, para a Igreja Católica, são considerados cristãos aqueles/as que receberam o sacramento da iniciação cristã o Batismo. Muitas pessoas responderam que são católicas apenas por tradição familiar. Na continuidade da pesquisa, procurou-se saber das pessoas entrevistadas se haviam recebido a primeira comunhão e, surpreendentemente, apenas 5.584 pessoas afirmaram que a tinham recebido, sendo que 3.545 disseram ainda não ter se preparado para esse sacramento. Ao indagar sobre o sacramento da Crisma, a pesquisa surpreendeu mais uma vez, pois pouco mais da metade da população católica dessa Paróquia recebeu o sacramento: 4.250 ainda não foram crismados. Portanto, após o sacramento do Batismo, há um número significativo de católicos que não realizaram a primeira comunhão e tampouco a Crisma.

E por fim, para contemplar as principais exigências normativas da fé católica, procurou-se saber se os casais realizaram o Sacramento do Matrimônio na Igreja Católica, considerando o total de 3.675 famílias entrevistadas (pergunta 1). O resultado foi o seguinte: 1.845 casais celebraram o sacramento do matrimônio; 1.830 não receberam o sacramento do matrimônio e, desse mesmo grupo, somente 742 casais desejam casar-se na Igreja Católica. No entanto, 1.088 casais já com filhos nem pensam na possibilidade de realizar o sacramento do matrimônio. Diante dos fatos numéricos, pode-se dizer que a participação nos sacramentos não é bastante baixa. O gráfico a seguir demonstra esses dados. 
Religare, ISSN: 19826605, v.16, n.2, dezembro de 2019, p.636-658

Gráfico 5 - Sendo sua família Católica, todos receberam os sacramentos?

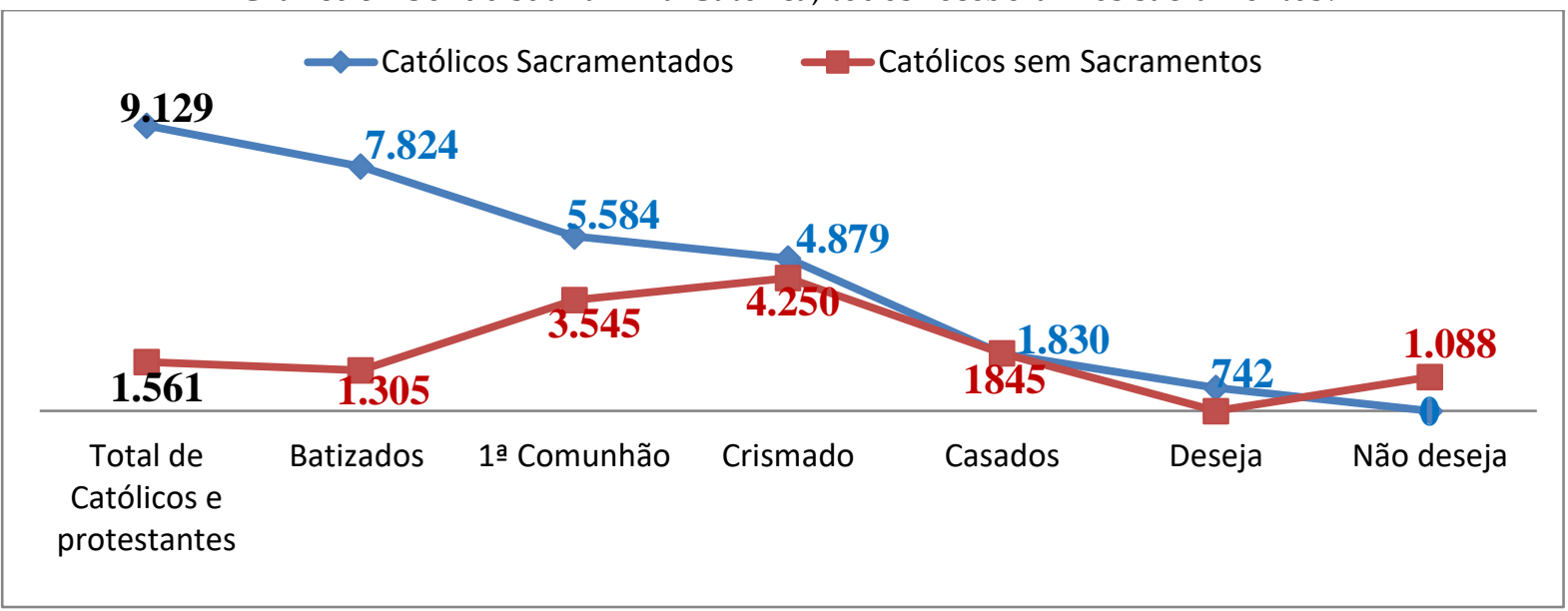

Fonte: dados da pesquisa - tabela 1

Ao visualizar os dados acima, é possível perceber que da população pesquisada, 14\% (1.561) professam sua fé nas igrejas protestantes, $85 \%$ afirmam ser católicos e 1\% participam de ambas as igrejas. Porém, quando os resultados foram tabulados, percebeu-se que $14 \%$ dos fieis que afirmam ser católicos ainda não foram batizados. $\mathrm{O}$ leque vai se abrindo de forma comprometedora para a instituição católica quando se chega à conclusão que 39\% dos católicos ainda não fizeram a primeira comunhão e 47\% não receberam o sacramento do Crisma. De modo geral, 50\% das famílias católicas não são casadas na Igreja e, ao serem perguntadas se desejariam casar, 71\% afirmaram que não e somente 29\%desejam realizar o sacramento do matrimônio. Portanto, embora a população católica seja hegemônica no município, a participação efetiva nas práticas religiosas/sacramentais não ocorre com regularidade.

A seguir, apresentam-se três gráficos: o primeiro demonstra como se dá a divisão numérica entre católicos e protestantes e aqueles que participam de ambas as igrejas, numa dupla pertença; o segundo apresenta o distanciamento dos católicos em relação aos Sacramentos (Batismo, Primeira Comunhão/Eucaristia, Crisma) da Igreja Católica; e o terceiro gráfico apresenta o quadro mais preocupante para Igreja, relacionada ao Sacramento do Matrimônio. 


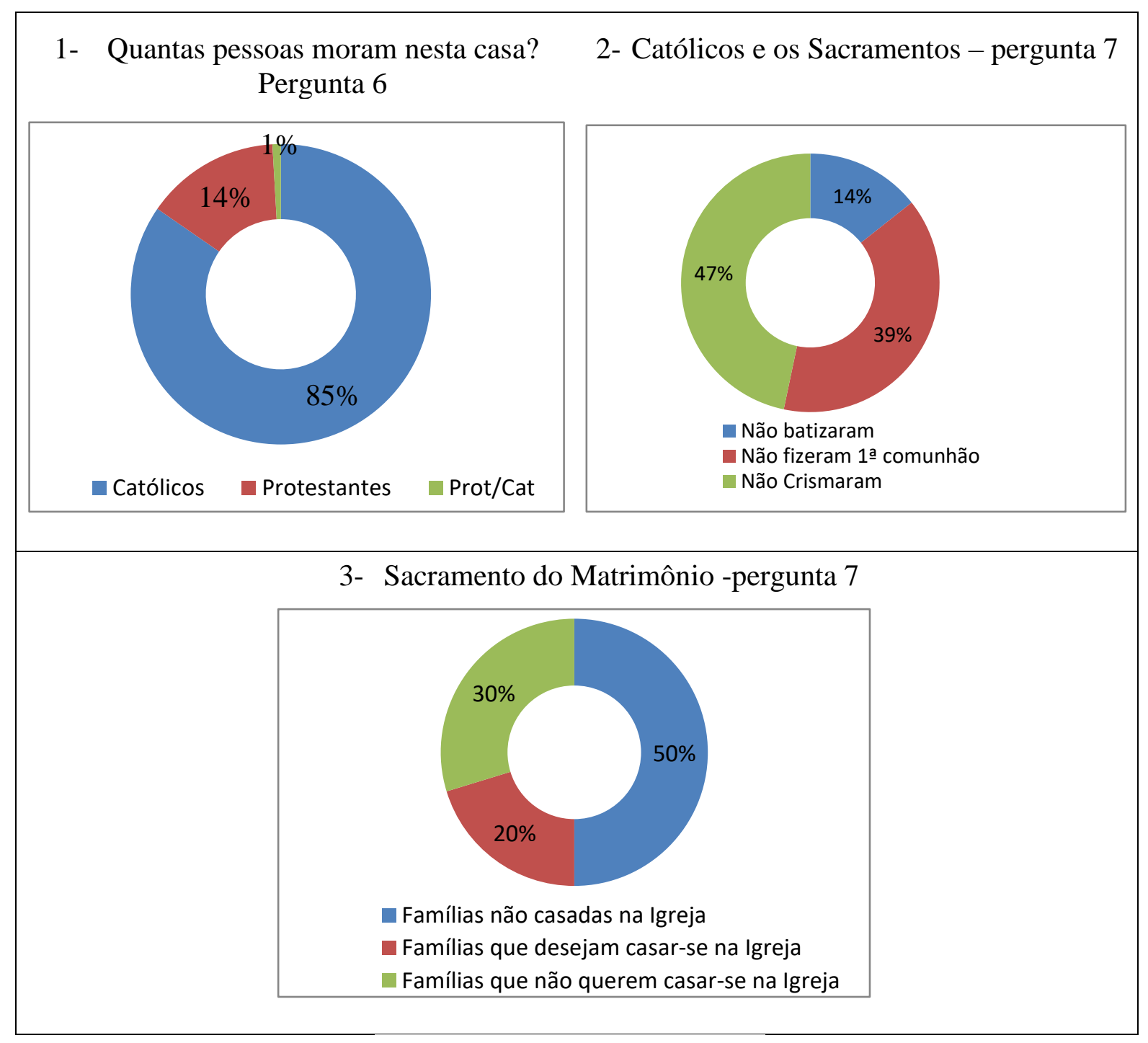

Fonte: dados da pesquisa - tabela 2

Que análise pode ser feita a partir dos dados apresentados da pesquisa realizada pelas Santas Missões Populares na Paróquia São Sebastião, na cidade de Carlos Chagas, Diocese de Teófilo Otoni? Percebeu-se que após o Batismo há um grande número de fiéis católicos que não seguem o catolicismo. O Batismo, geralmente realizado quando criança, não significa uma fidelidade à tradição católica. Por outro lado, a educação religiosa oferecida pela Igreja Católica às pessoas que dela participam também é deficitária. O trabalho da ICAR, muitas vezes, resume-se a catequese para a primeira Comunhão, Crisma e a realização de missas, com um discurso verticalizado e com pouca margem para a participação dos leigos. A pesquisa demonstra que o catolicismo está em processo de transformação, isto é, não são mais os Sacramentos 
que mantém os fiéis na Igreja. Neste sentido, percebe-se uma desafeição à instituição, como apontando por Oliveira (2012) muito mais do que um trânsito religioso. Há uma desafeição em relação à Igreja Católica que se mostra na pouca participação nas missas. Percebeu-se também um afastamento do fiel em relação à prática dos Sacramentos. O Batismo é o Sacramento ainda mais realizado, seguido da primeira comunhão, mas a Crisma e o Casamento são menos praticados. Oliveira aponta que a não participação nas missas aponta para a desafeição ao catolicismo.

No caso do catolicismo romano, a desafeição se expressa pela ausência à missa dominical. Não por acaso, foram às pesquisas sobre a prática dominical que motivaram a teoria da pertença/desafeição religiosa: além de ser um ato religioso, a missa confirma o compromisso do fiel com a Igreja e é fundamental para a influência da religião na sociedade, porque é a atividade molecular dos fiéis que dá força social à Igreja (OLIVEIRA, 2012, p. 1251).

A pesquisa realizada mostrou que somente 1.014 famílias são participantes ativas nas celebrações/missas. No entanto, 1.784 famílias responderam que vão poucas vezes às celebrações/missas. Participam somente em momentos importantes: no dia em que os filhos recebem algum Sacramento, ou em casamentos de amigos e às vezes nas missas de sétimo dia de parentes e amigos próximos. Surpreendeu o dado de que 785 famílias nunca vão à Igreja e 92 famílias participam de mais de uma religião. Percebe-se que o sentimento de não pertença à comunidade católica é um crescente. $\mathrm{O}$ fiel continua ligado ao sagrado, mas já não quer e não participa da instituição igreja, há um afastamento dos Sacramentos e pouca participação nas missas.

Poderíamos suspeitar que o "não ir à missa" e "não participar dos Sacramentos" ser uma forma subversiva dos fiéis estarem dizendo, queremos outro tipo de igreja, que não seja somente sacramental. Esta suspeita sugere uma continuidade na pesquisa sobre formas da reorganização dos catolicismos. Percebemos que a pesquisa não apontou para um trânsito religioso para outras denominações, mas uma desafeição, não participação da vida comunitária.

\section{Considerações gerais}


Religare, ISSN: 19826605, v.16, n.2, dezembro de 2019, p.636-658

A partir da pesquisa nas trinta e duas comunidades da paróquia São Sebastião, cidade de Carlos Chagas - MG, empreendida através das Santas Missões Populares percebeu-se que a Igreja Católica está em movimento. A paróquia de São Sebastião é formada por uma população hegemonicamente rural, mesmo que não tenha se constatado um grande trânsito religioso, percebeu-se, no entanto, uma desafeição com a tradição religiosa, tal como entende o sociólogo Oliveira, citado acima, isto é, os fiéis não seguem mais todos os Sacramentos colocados pela ICAR como necessários para ser uma pessoa cristã. $\mathrm{O}$ catolicismo continua sendo numericamente a maior confissão religiosa da região de Teófilo Otoni e também da cidade de Carlos Chagas, mas depois do Sacramento do Batismo, muitos/as já não são crismados e tampouco recebem o Sacramento do Matrimônio. Também a participação nas celebrações/missas semanais é pequena. Constatou-se que as pessoas se retiraram da participação efetiva na ICAR, mas também não foram para outra denominação religiosa.

Percebe-se a falta de sentimento de pertença e de afetividade com a comunidade religiosa e sua forma de se organizar. Ao mesmo tempo há poucos padres para o atendimento de muitas comunidades católicas. Percebe-se que o catolicismo está em transformação. Já não basta mais a realização dos Sacramentos para o pertencimento à Igreja - e este fato é bastante perceptível na área urbana. Na área rural a pertença/a afeição religiosa ao catolicismo é ainda bastante alto. A organização da vida cotidiana já não é mais marcada pelo badalo dos sinos ou pelos ritos sacramentais. Neste ponto, concorda-se com Danièle Hervieu-Léger, para quem há uma profunda crise de transmissão da cultura e da identidade religiosas. Os universos geracionais têm rompido os laços entre si, rompimento que não ocorre apenas no âmbito religioso, mas também no familiar, educacional e político - no sentido amplo (2005, p. 65).

Neste sentido, a pesquisa mostrou a necessidade de um repensar da Igreja Católica, criando uma maior afeição/sentimento de pertença entre as pessoas participantes do catolicismo e suas lideranças, afirmando na própria instituição os valores éticos que afirmam o cuidado responsável com todas as pessoas e com toda a criação, como apontado por Oliveira (2012, p. 1230-1254). Afirma-se que a pesquisa 
Religare, ISSN: 19826605, v.16, n.2, dezembro de 2019, p.636-658

realizada pela Paróquia São Sebastião, Diocese de Teófilo Otoni, mostrou que o catolicismo está interessado no que está acontecendo em suas comunidades e constatou-se um catolicismo em transformação.

Este catolicismo que ganha novos contornos é marcado, em maior ou menor grau, pelas transformações da sociedade contemporânea, que envolvem mudanças na forma das famílias se organizarem, por exemplo. Os fieis vivem a experiência do crer de maneira diversificada e pouco institucionalizada. $\mathrm{O}$ ethos comunitário, tradicionalmente associado ao catolicismo, tem sido profundamente alterado pela privatização da religião e a vivência individualista da religião. Portanto, os rituais e as práticas sacramentais têm recebido uma valoração diferente tempos pretéritos. Desta forma, a crise de pertença religiosa pela qual passa a Igreja Católica é uma crise dos próprios laços identitários que unem os fieis às comunidades. Superar esse estado de coisas e encontrar novos caminhos de transmissão da cultura religiosa é a condição sine qua non de sobrevivência. É necessário reconhecer que há também muitos catolicismos que convivem lado a lado, sendo, no entanto, necessário fortalecer os laços afetivos e de pertença. A pesquisa demonstrou que há um tipo de catolicismo, o qual se firma na realização dos Sacramentos, em mutação.

\section{Referências}

ALMEIDA, Ronaldo de; MONTERO, Paula. Trânsito religioso no Brasil. São Paulo em Perspectiva, v.15, n. 3, p. 92-101, 2001. Disponível em: https://bit.ly/355HM6l. Acesso em: 20 jun. 2019.

AZEVEDO, Thales de. O catolicismo no Brasil: um campo para a pesquisa social. Salvador: Edufba, 2002.

BARTZ, Alessandro. Múltiplas pertenças, desinstitucionalização e desregulação da crença: refletindo a modernidade religiosa no Brasil. Protestantismo em Revista, v. 25, p. 8-18, 2012. Disponível em: https://bit.ly/2pgnGqx. Acesso em: 24 maio 2019.

BERGER, Peter. O dossel sagrado: elementos para uma teoria sociológica da religião. Org. Luiz Roberto Benedetti. Trad. José Carlos Barcellos. 5. ed. São Paulo: Paulus, 2004. (Coleção sociologia e religião; 2)

BENCKE, Romi Marcia. Sobre as Tensões e as ambiguidades Relacionadas à presença das Religiões na Esfera Pública. Reflexus, Ano IX, n. 14, p. 243-255, 2015/02. Disponível em: https://bit.ly/2K155AU. Acesso em: 22 jun. 2018. 
BOURDIEU, Pierre. "A dissolução do religioso". In: BOURDIEU, Pierre. Coisas ditas. São Paulo: Brasiliense, 1990.

CARRANZA, Brenda. Renovação carismática católica: origens, mudanças e tendências. Aparecida: Santuário, 2000.

CENSO INSTITUTO BRASILEIRO DE GEOGRAFIA E ESTATÍSTICA (IBGE). Religião 2010. Disponível em: https://bit.ly/3718WwM. Acesso em: 25 mar. 2019.

COSTA, Emerson Roberto da. O trânsito religioso e a recomposição das formas religiosas na Igreja Assembleia de Deus, ministério São Bernardo do Campo. Dissertação (Mestrado em Ciências da Religião) - UMESP, São Bernardo do Campo, 2011.

COELHO, Lázara Divina. Trânsito religioso: uma revisão exploratória do fenômeno brasileiro. Vox Faifae, v. 1, n. 1, p. 1-24, 2009. Disponível em: https://bit.ly/2CFPurp. Acesso em: 25 jun. 2019.

COMUNIDADE EVANGÉLICA DE CONFISSÃO LUTERANA EM TEÓFILO OTONI - CETO. Disponível em: https://bit.ly/32HPFgn. Acesso em: 22 maio 2019.

DIOCESE DE TEÓFILO OTONI. Diretrizes da Ação Evangelizadora 2004 - 2007. Gráfica Expresso Ltda. Teófilo Otoni - MG, 2003.

DOMEZI, Maria Cecilia. Religiões na história do Brasil. São Paulo: Paulinas, 2015.

ENTREVISTAS REALIZADAS por Wagner Ferreira Vaz em 2017.

FRESTON, Paul. Breve histórico do pentecostalismo brasileiro. In: ANTONIAZZI, Alberto et al. Nem anjos nem demônios: interpretações sociológicas do pentecostalismo. Petrópolis: Vozes, 1994.

HERVIEU-LÉGER, Danièle. O peregrino e o convertido. A religião em movimento. Tradução de Catarina Silva Nunes. Lisboa: Gradiva, 2005.

. O peregrino e o convertido: a religião em movimento. Petrópolis: Vozes, 2008.

IBGE. Teófilo Otoni. Disponível em: https://bit.ly/2NLnbyo. Acesso em 20 abr. 2019.

IBGE. Mantena. Disponível em: https://bit.ly/2KnfQmu. Acesso em: 20 abr. 2019.

LEONEL, Guilherme. Campo religioso brasileiro na contemporaneidade: continuidade, descontinuidade, transformações e novos ângulos de análise. Interseções, v. 12, n. 2. p. 382-407, dez. 2010. Disponível em: https://bit.ly/2pkYwXY. Acesso em: 20 jun. 2019.

OLIVEIRA, Pedro Assis Ribeiro de. Pertença/desafeição religiosa: recuperando um antigo conceito para entender o catolicismo hoje. Horizonte, v. 10, n. 28, p. 1230-1254, out.-dez. 2012. Disponível em: https://bit.ly/2KhSajq. Acesso em: 25 maio 2019.

TEIXEIRA, Faustino. Faces do catolicismo brasileiro contemporâneo. REVISTA USP, São Paulo, n. 67, p. 14-23, set.-nov. 2005. Disponível em: https://bit.ly/33GRiMN. Acesso em: 20 jul. 2019.

SCHÜNEMANN, Rolf. Do gueto à participação: o surgimento da consciência sociopolítica na IECLB entre 1960 e 1975. São Leopoldo: Sinodal, 1992.

ZEPEDA, José de Jesús Legorreta. Secularização ou ressacralização? O debate sociológico contemporâneo sobre a teoria da secularização. Revista brasileira de Ciências Sociais, v. 25, n. 73, p. 129-178, 2010. Disponível em: https://bit.ly/2XioUhB. Acesso em: 20 abr. 2019. 
Religare, ISSN: 19826605, v.16, n.2, dezembro de 2019, p.636-658

Recebido em 04-09-2019.

Aprovado em 14-11-2019. 